\title{
Confronting Mathematical Pseudo-Community: A Domain-specific Analysis of a Middle School Mathematics Department
}

\author{
Paul Weinberg ${ }^{1^{*}}$ \\ ${ }^{1}$ Oakland University, Rochester, Michigan, USA
}

Received 19 May 2018 - Revised 28 December 2018 - Accepted 1 January 2019

\begin{abstract}
Teacher professional community refers to the extent to which teachers collaborate to further their own and their students' learning. Peck (1995) drew distinctions between pseudo-community and professional community, where pseudo-communities rely on suppression of conflict and the tacit understandings that it is "against the rules" to challenge others' beliefs and ideas. The teacher education literature is predominantly composed of domain-general characterizations of teacher community. This study investigates the pseudo-communities of five middle school mathematics teachers' through a domain-specific characterization of criteria of professional community. These characterizations are made using teacher responses to surveys and interaction analysis during a meeting between middle school mathematics teachers and researchers. These analyses allow for the investigation of why domain-general characterizations of pseudo-community may be limited.
\end{abstract}

Keywords: mathematics education, in-service teacher education

\section{INTRODUCTION}

In defining communities of practice Lave and Wenger (1991; Wenger, 1998) provided criteria by which to distinguish true communities from mere groups of individuals involved in similar work: joint enterprise, mutual engagement, and a shared repertoire. Wenger argued that a group has achieved the status of "community" if and only if it is working collaboratively on a project in accordance with a set of norms of practice and with a language and set of tools that are specific to the community. Little $(1982 ; 2012)$ presented four "critical practices of adaptability" that focus specifically on teacher communities of practice and add to the work of Wenger. Little suggested that these teaching communities should "engage in frequent, continuous, and increasingly concrete and precise talk about teaching practice; be frequently observed and provided with useful critiques of their teaching; plan, design, research, evaluate, and prepare teaching materials together; and teach each other the practice of teaching." (p. 331) Analysis by Borko (2004), Shulman and Wilson (2004), Franke, Carpenter, Levi, and Fennema (2001), and the Center for Research on the Context of Secondary School Teaching (CRC) (McLaughlin, 1993; McLaughlin \& Talbert, 2006) further suggests that a focus on students' understanding is necessary for a professional community of teachers. In addition, Avalos (2011), DuFour (2004), Louis, Kruse, and Marks (1996), described activities that are critical to a teaching community. Louis, Kruse, and Marks suggested that "peer coaching relationships, teamed teaching structures, and structured classroom observations are methods used to improve both classroom practice and collegial relationships" (p. 760). Adding to this conceptualization of professional teaching communities, researchers (e.g., Horn \& Kane, 2015; Stoll \& Louis, 2007; Tharp \& Gallimore, 1988) have highlighted trust as requisite. Similarly, in their studies of urban elementary school teachers, Bryk, Camburn, and Louis (1999) and Bryk and Schneider (2003) found the strongest predictor of professional community was social trust among faculty. Likewise, Eaker, DuFour, and DuFour (2002) cited trust as one of three foundational aspects (time and mutual commitment being the other two) for creating professional communities of teachers. Newmann and Associates (1996) and Gamoran, et al. (2003) presented five key aspects of a teachers' professional community that support the findings from the above research: (a) a shared sense of purpose; (b) a collective focus on student

(C) 2019 by the authors; licensee Modestum Ltd., UK. This article is an open access article distributed under the terms and conditions of the Creative Commons Attribution License (http://creativecommons.org/licenses/by/4.0/). \weinberg@oakland.edu (*Correspondence) 


\section{Contribution of this paper to the literature}

- Provides domain-specific principles and criteria with which to describe a teacher professional community.

- Provides a domain-specific characterization of a pseudo-community within a middle-school mathematics department based upon the professional teaching community literature.

- Provides a means to consider how to develop from a pseudo-community to a professional community of mathematics teachers.

learning; (c) collaborating to improve students' understanding of mathematics; (d) engaging in reflective dialogue about their instructional practices; and (e) making their own teaching practices public.

Grossman, Wineburg, and Woolworth $(2000 ; 2001)$ noted that professional teaching communities do not emerge spontaneously. As a professional teaching community begins to develop, there is a natural tendency by individuals to "play community" to act as if they are already a community that shares values and beliefs, focuses on student learning, collaborates to improve students' understanding of mathematics, engages in reflective dialogue about their instructional practices, and has sufficient trust to make their own teaching practices public. Grossman et al. (2000; 2001) described how the maintenance of pseudo-community pivots on the suppression of conflict where faceto-face interactions are regulated by a tacit understanding that it is "against the rules" to challenge others or press them too hard for clarification. Pseudo-community supports discourse that is casual, superficial, and at times explicitly and intentionally fails to address many (if not all) of those elements that make up professional teaching community.

Much work around the development of pseudo-community (e.g., Grossman, Wineburg, \& Woolworth, 2000; 2001; Lieberman, Miller, Wiedrick, \& von Frank, 2011; Little, 2012) has focused on the development of domaingeneral criteria. Although these domain-general criteria of pseudo-community are useful towards generic understandings of how teacher development advances towards professional community, they are limited in their applicability to how these domain-general principles apply within particular domains (e.g., secondary mathematics). Domain-general models of learning focus on general cognitive structures for knowledge development, while domain-specific models focus on cognitive structures that are highly dependent on context. Some recent work in mathematics education has focused on domain-specific models of teacher learning. These domain-specific models have focused exclusively on how pre- and in-service teachers learn to consider and implement instruction within specific mathematical contexts. For example, Hill et al. (2008) and Hill (2010) described the domain-specific development of mathematical knowledge for teaching (MKT), comprised of mathematical disciplinary knowledge and mathematical knowledge for instruction. The current study improves upon previous domain-general characterizations of professional learning by focusing on domain-specific principles present (or absent) within a pseudo-community. Investigating the domain-specific practices of a group of teachers allows for a more adequate differentiation between professional and pseudo-community of mathematics teachers.

\section{THEORETICAL FRAMEWORK}

The definition of professional community that is referenced in this study is that enumerated by Newmann and Associates (1996) and Gamoran and colleagues (2003). However, because these authors framed these categories as domain-general, I have modified them for domain-specific contexts within this study. I have altered four of the five presented categories in order to describe domain-specific pseudo-communities (i.e., of mathematics teachers). There is one category that was described by the authors as having a domain-specific focus: collaborating to improve students' understanding of mathematics. This category is included in the study in its original domain-specific form. Domain-specific elements that have been added to the remaining four categories are shown parenthetically: a shared sense of purpose (around mathematics teaching), collective focus on student learning (about mathematics), engaging in reflective dialogue about their (mathematical) instructional practices, and making their own (mathematical) teaching practices public.

The term "pseudo-community" has been used in various ways. Peck (1995), Grossman, Wineburg, and Woolworth (2000; 2001), Lieberman, Miller, Wiedrick, and von Frank (2011), and Little (2012) have used the term to focus on face-to-face relations and professional collaborations amongst groups of teachers that appear congenial because the expression of conflict and dissent is squelched. These interactions and collaborations rarely focus on central issues of teaching and learning. In this study I develop an understanding of pseudo-communities of mathematics. 
Table 1. Participants

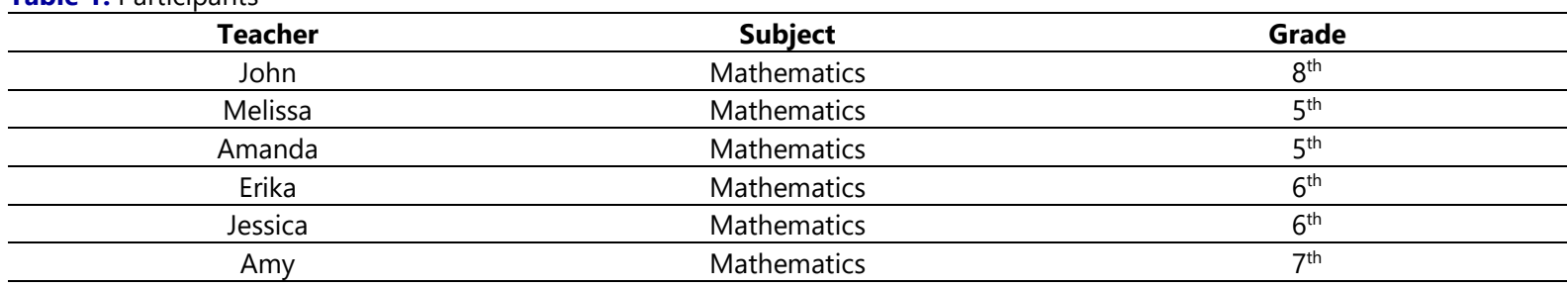

\section{Research Questions}

This study focuses on the following research questions: (a) To what extent do middle school mathematics teachers represent a professional or pseudo-community and (b) in what ways do a focus on domain-specific practices affect the characterization of professional or pseudo-community?

\section{METHODS}

This is a mixed methods study that includes quantitative analysis of survey data and qualitative interaction analysis of video data.

\section{Participants}

The sample is shown in Table 1. The participants were all middle school mathematics teachers $(n=6)$ from a public middle school in the southeastern United States.

The teachers participating in this study were predominantly female (male $=1)$ and White. The collaboration between teachers and researchers came about when the school principal reached out to the author to lead a professional development. This professional development included a series of participant-observations, where the mathematics department chair (Erika) took on the role of a student in her colleagues' classes.

\section{Procedure}

Prior to a meeting between the mathematics teachers and the researchers (i.e., the teacher-researcher meeting), the Teacher Pre-Study Survey (Appendix A) was distributed to the teachers. These surveys were composed of nineteen questions that targeted elements of professional community. The teachers returned the completed surveys and submitted them to the researchers during the teacher-researcher meeting. This meeting was video recorded.

Teacher Pre-Study Survey. The teacher survey measures teachers' perceptions of the support structures for developing instructional practices in mathematics (Appendix A). It includes items concerning (a) the level of teachers' participation in mathematical teacher networks, their propensity to offer instructional advice, and who they offer advice to; (b) the degree to which the interactions between teachers in these networks focus on mathematical concepts and how to relate them to students' reasoning; (c) the degree to which teachers have a shared vision for mathematics instruction and student learning; and (d) the professional development that teachers have received in support of improved instructional practices in mathematics.

Teacher-researcher Meeting. All teachers in this study consented to participate in a professional development that would implement a novel model of peer observation. The researchers met with the six middle school mathematics teachers at one time, for approximately two hours to plan for the professional development. This teacher-researcher meeting was video-recorded and rendered for further analysis.

\section{Analysis}

Teacher Pre-Study Survey. The survey results were categorized according to five criteria domain-specific categories, informed by the work of Newmann and Associates (1996) and Gamoran and colleagues (2003): a shared sense of purpose (around mathematics teaching), collective focus on student learning (about mathematics), engaging in reflective dialogue about their (mathematical) instructional practices, and making their own (mathematical) teaching practices public. Two researchers coded the responses into all five categories. The interrater agreement was $92 \%$. Because the data are ordinal, Mann-Whitney $U$ tests were conducted to compare the mean teacher Likert scores with those scores corresponding with not engaging in the activity the survey questions targeted. 
Teacher-researcher Meeting. Transcripts were created from the video data collected from the teacherresearcher meeting. Using interaction analysis (Jordan \& Henderson, 1995), the researchers characterized participant talk (from the transcripts) into the five categories above (e.g., shared sense of purpose around mathematics teaching). The analysis of the transcription is triangulated with results from the Teacher Pre-Study Survey.

\section{RESULTS}

Data from the survey and meeting analyses indicated that the teachers did not have a shared sense of purpose (around mathematics teaching), a collective focus on student (mathematics) learning, engage in collaboration to improve students' understanding of mathematics, engage in reflective dialogue about their (mathematical) instructional practices, or make their own (mathematical) teaching practices public.

\section{Shared Sense of Purpose (around Mathematics Teaching)}

These teachers indicated the absence of a shared sense of purpose around mathematics teaching. For example, no two teachers had ever observed one another's mathematics teaching ( $1 \mathrm{~b}, M d n=0 ; 4 \mathrm{a}, M d n=0 ; 4 \mathrm{~b}, M d n=0)$ (Appendix B). In addition, teachers indicated that they did not jointly plan mathematics instruction $(6 \mathrm{e}, M d n=0.5)$, share materials related to mathematics instruction with colleagues ( $6 f, M d n=1)$, all use mandated state mathematics standards $(6 \mathrm{j}, M d n=0.5)$, or jointly analyze student work in mathematics $(6 \mathrm{k}, M d n=0.5)$. Moreover, teachers disagreed with colleagues about how to teach mathematics ( $3 c, p<0.05$, Mann - Whitney $\mathrm{U}$ test) and were unaware of how their colleagues taught it (3f, $p<0.05$, Mann - Whitney U test).

During the teacher-researcher meeting, CM (one of the researchers) tried to focus a discussion on Erika's upcoming observations of her colleagues (the central component of the upcoming professional development). $\mathrm{CM}$ tried to support Erika to think about mathematics teaching and learning. However, the group of teachers had no shared practices to support Erika to discuss issues central to mathematics instruction (Interview Transcript 1).

Interview Transcript 1

CM: $\quad$ What are you coming into this [observation] expecting?

Erika: I'm hoping if there are certain things I see with students that are more effective, like certain lines of questioning. Or, things that aren't as effective like certain days when we think we're on it, but the students miss the boat. We think that we've taught it; I know for a fact there are things that I think I've taught the fire out of and [students] take the test and it's as if you never taught it before (pause) as if they've never seen it before...Maybe if I see a student light bulb somehow [I will make a note in my journal], maybe a comment about the process that got them [students] to it.

Erika's response suggested that there was a shared sense of purpose, but not around mathematics teaching. She had nebulous, superficial, and conflicting ideas about what areas in mathematics teaching and learning were worth investigating. Her ideas were not sufficiently clarified to support a common language or understanding of mathematics teaching among her colleagues. For instance, Erika noted that she was interested in investigating "certain lines of questioning" or "things that aren't as effective [for students]," when teachers believe they've "taught it." However, these topics were too broad to be productively engaged with her colleagues.

Frequently, teachers indicated that the element of their mathematics instruction that they wanted Erika to focus on were those that did not involve mathematics (i.e., a domain-general shared sense of purpose). Accordingly, it is difficult to have a shared sense of purpose around mathematics teaching absent any discussion of mathematics teaching (Interview Transcript 2).

Interview Transcript 2

Amanda: And I told [Erika] I wanted to know if I have some strange tick. Or if I say "Okay" [too frequently].

Amanda was concerned about the number of times she said, "okay," "alright," and "be sure you're listening" within a teaching lesson. These topics show a general shared sense of purpose. However, mathematics teachers must indicate a shared sense of purpose around mathematical pedagogical and disciplinary practices.

\section{Collective Focus on Student Learning (of Mathematics)}

The survey data did not show a collective focus on student learning of mathematics. Teachers indicated that their colleagues did not support them to facilitate mathematical classroom discussions $(12 \mathrm{~d}, M d n=$ 1.0) (Appendix B)or mathematical group work $(12 \mathrm{e}, M d n=1.0)$, where students were encouraged to share their 
thinking. In addition, administrators did not provide teachers with feedback to improve their mathematics instruction $(10 \mathrm{~b}, M d n=1.5)$.

Two concepts were raised by these mathematics faculty that could be categorized as peripherally focusing on student learning of mathematics: procedural fluency and higher order thinking (Interview Transcript 3).

Interview Transcript 3

Amanda: I [often] see a child who is caught up in the [procedures] and they're not thinking past just the [procedures]. [I am concerned with student] (pause) fear of the [procedures because I want to] go to the next level with them [(i.e., focus on conceptual understanding)] ...With the [gifted and talented] children, I want to know if I'm asking questions that promote the higher order thinking. Am I making them think, or am I really going after the [procedures]? I don't want to not do [procedures], but I want to make sure we go beyond it [to concepts]. Are my questions leading to that or are they not?

The discussion of procedural fluency and higher order thinking indicated a collective focus on student learning, but not a collective focus on student learning of mathematics. For example, procedural fluency and higher order thinking are described in vague and non-specific terms; accordingly, there is little possibility for a collective focus on student learning of mathematics. Amanda raised procedural fluency in an attempt to discuss student thinking. Procedural fluency is defined as knowledge of procedures, knowledge of when and how to use them appropriately, and skill in performing them flexibly, accurately, and efficiently; accordingly, conceptual understanding refers to an integrated and functional grasp of mathematical ideas (Mathematics Learning Study Committee, 2001). Amanda discussed how "higher order thinking" was impeded by an exclusive focus on procedures. Resnick (1987) defines higher order thinking as requiring non-algorithmic, complex, multiple possible solutions, nuanced judgment and interpretation, the application of multiple criteria, uncertain solutions to posed problems, self-regulation, imposing meaning, and effortful thinking.

Although teachers were attentive to difficulties that occur when there is an exclusive focus on mathematical procedures, without a clear conception of the relation between mathematical concepts and procedures, it is unlikely that the teachers would be able to effectively communicate about these aspects of student learning of mathematics. When further reflecting on what about student thinking in mathematics she plans to attend to during her observation, Erika raised the construct of "engagement." She considered how engaged she would be when she participated as a student in her colleagues' classes (Interview Transcript 4).

\section{Interview Transcript 4}

Erika: [When thinking about what I will focus on during my observations, I will think about] how actively engaged was I with the activity, how much time on task? Was there some time when I wasn't spending doing things?

Erika discussed the construct of engagement with no connection to student mathematical learning.

\section{Collaborating to Improve Students' Understanding of Mathematics}

Teachers indicated that while they had addressed mathematical concepts in professional development sessions $\left(13 \mathrm{~d}_{1}, p<0.05\right.$, Mann - Whitney U test; $13 \mathrm{f}_{1}, p<0.05$, Mann - Whitney U test) (Appendix B), either such work did not impact their instruction or they were unable to describe how it had $\left(13 \mathrm{~d}_{2}, M d n=2.0 ; 13 \mathrm{f}_{2}, M d n=1.5\right)$. Teachers also indicated that the administration had not structured sufficient time for collaboration around mathematics teaching $(7, M d n=0.5)$. In addition, the administration had not supported professional development or collaboration around mathematics teaching and learning, beyond that required by the school district $(12 \mathrm{j}, M d n=$ 2.0). For example, the administration had never supported teachers to engage students with challenging nonroutine mathematical tasks $(12 \mathrm{~h}, M d n=2.0)$. Although some professional developments focused on leading classroom discussions where students were to mathematically justify their answers $\left(13 \mathrm{e}_{1}, M d n=2.5, p<0.05\right)$, support high level mathematical tasks $\left(13 \mathrm{~g}_{1}, M d n=2.0, p<0.05\right)$, and engage students in high level mathematics $\left(13 \mathrm{i}_{1}, M d n=2.5, p<0.05\right)$, teachers were not supported to incorporate these practices into their teaching $\left(13 \mathrm{e}_{2}, M d n=2.0,13 \mathrm{~g}_{2}, M d n=2.0,13 \mathrm{i}_{2}, M d n=3.0\right)$. Moreover, through professional development teachers were neither supported to provide students with high level mathematics solutions $\left(13 \mathrm{~h}_{1}, M d n=1.0\right)$ nor able to incorporate these practices into their teaching $\left(13 \mathrm{~h}_{2}, M d n=2.0\right)$. Thus, there was insufficient and ineffective collaboration around central mathematical teaching practices.

John, a first-year teacher, evidenced collaboration to improve students' understanding, but not collaboration to improve students' understanding of mathematics. John began a discussion with Erika that showed how collaboration around mathematics teaching, within a pseudo-community, breaks down. John began a discussion about mathematical content. He raised his concern about student difficulties with operations on fractional numbers with Erika (Interview Transcript 5). 
Interview Transcript 5

John: Fractions - you know I told you a while back that like half my kids couldn't add and subtract fractions...They just don't want to do the work.

Erika: They don't want to think.

John: They don't want to do anything...

Erika: Well, I don't know where to help you.

This discussion indicated the presence of a mathematical pseudo-community. John raised a concern he had about his students understanding of an important Common Core State Standard (National Governors Association, 2010) (e.g., adding and subtracting fractions). This created an opportunity for these teachers to engage in collaboration around student understanding of mathematics around this content. However, the topic focus changed from content to student indolence: "They just don't want to do the work." This derailed the conversation to one where Erika could exit with a simple superficial: "Well, I don't know where to help you." Next, Melissa presented another opportunity to engage in collaboration around student understanding of mathematics, which quickly devolved into superficial and general discussion (Interview Transcript 6).

\section{Interview Transcript 6}

Melissa: [Erika's observation of my instruction will begin] at a part of the curriculum that is review...[I]f you [would observe me] during fractions, I had a million fun things to do, lots of manipulatives; lots of fun things to do. If you came during lots of geometry we did a lot of cool activities. Now, we're doing multiplying, multiplying 3-digits by 2 [digits], whatever. And it's not a very exciting part of our curriculum. So, when you're sitting there in my class I want you to just (pause) if a good idea pops into your head, I just want you to [tell me].

Although this collaboration was about mathematical content, Melissa presented a view that did not address specific issues within the content. Her view seemed to be that mathematics content is either exciting or not. When she described her unit on fractions, she indicated that she "had a million fun things to do, lots of manipulatives." This characterization of fractions as fun neglected to focus on the complexity of the big ideas within the content (e.g., part-whole relations, representing fractions using linear measure, equivalence of fraction).

Melissa next described the importance of engaging in mathematics with real world applications (Interview Transcript 7). Again, the focus deviated from student understanding of mathematics.

Interview Transcript 7

Melissa: So, maybe something that helps them see [how this content is important] (pause) I do use this all the time (pause) I talk about when you play football you don't just go out to practice and start playing football. You exercise and this is like exercise for your brain. I use that a lot for things when they can't really (pause) when it's hard to apply it to a real-life activity. You know, and the boys fall for that one. But um, if you can just find some way to make it so they'll just think, ah; that's why I need to know that or this is how I can apply that (pause). Geometry's easy to make relevant. I mean, my husband's an architect; I can always pull out the old (pause) this is a job where you use this. Or, if you're going to be an interior decorator or if you' re hanging curtains or anything like that.

Here, Melissa presented a conception of what types of mathematical ideas were important to teach. Melissa made an argument that mathematical ideas that are "relevant" are more compelling to students than those that are not. However, when probed it was not clear what she meant by relevant. To Melissa, mathematics was relevant if it helped students see how they could use mathematical ideas outside of the classroom and made clear that professions exist that use these mathematical concepts. In addition, when it was difficult to see how mathematical ideas applied outside of the classroom, Melissa used a "football" metaphor. She forced students (especially male students) to see that their mathematics was practice for what would one day be relevant.

With one exception, this group of teachers did not collaborate to improve students' understanding of mathematics. During that one exception, Erika described one big idea within number, the role of place value. This was a qualitatively different way of engaging with this content than Melissa's (or the other mathematics teachers) (Interview Transcript 8).

\section{Interview Transcript 8}

Erika: [With multiplication of 3 and 2 digit numbers,] (pause) if you had 324 times 25, [it's important] for [students] to understand that it's 324 times 20 and 324 times 5; that's why you add the extra zero.

Here, Erika initiated an important discussion that focused on mathematical ideas within the content. She explained how place-value operates in a base-10 number system, over multiplication. Unfortunately, Melissa 
responded by dismissing this important mathematical idea and restating how she believed Erika's observation could best benefit her; she asked Erika to let her know if she could come up with anything that might make the multiplication of 3 and 2-digit numbers fun, by letting Melissa know if she has any great activities. She was unaware that Erika's discussion of content was such a recommendation. Thus, Erika's turn-of-talk described student understanding of mathematics; unfortunately, her colleagues were unable to productively take up this topic. Accordingly, there was no collaboration.

\section{Engaging in Reflective Dialogue about their (Mathematical) Instructional Practices}

These teachers did not discuss mathematical instructional practices. For example, teachers did not discuss state mathematics standards $(6 \mathrm{j}, M d n=0.5)$ (Appendix B) or analyze student work $(6 \mathrm{k}, M d n=0.5)$. No one (teachers, administrators, or coaches) supported the development of new mathematical instructional practices $(12 \mathrm{n}, M d n=$ 1.0).

Amanda discussed one instructional practice that she employed (Interview Transcript 9). This indicates her engagement in a reflective dialogue about instructional practices, but not about mathematical instructional practices.

Interview Transcript 9

Amanda: When I question children, there are two roles that I play ... One is: I am the teacher. The other is: you are telling me, as a person who does not know...how to do something, how to do it. And I will go to that role when I see a child who is caught up in the [procedure] and they're not thinking past just the [procedure]. So, they're going to talk me past the [procedure]...

Amanda attempted to engage in reflective dialogue about a pedagogical practice she employed. Within this practice, when she determined that a student did not understand the concept behind a procedure she required them to explain the procedure. Explanation and justification have been found to be a valuable mathematics disciplinary practices (Yakel \& Cobb, 1996). However, neither Amanda nor her colleagues could engage in a reflective dialogue about mathematical instructional practices because (a) Amanda could not clarify the mathematics involved in this practice and (b) her colleagues did not indicate that they engaged in similar practices.

\section{Making their own (Mathematical) Teaching Practices Public}

No two teachers had observed each other's mathematical teaching $(4 \mathrm{a}, M d n=0.0 ; 4 \mathrm{~b}, M d n=0.0 ; 12 \mathrm{k}, M d n=$ 1.0) (Appendix B). In addition, all teachers indicated they possessed little knowledge of their mathematics colleagues' teaching methods ( $5 a \mathrm{p}<0.05$, Mann - Whitney U test) or the content they covered ( $5 \mathrm{~b}, \mathrm{p}<0.05$, Mann Whitney U test).

The teacher-researcher meeting further indicated that this group of teachers had spent little time making their mathematics teaching practices public. In fact, they had spent little time making any of their teaching public. Amanda noted that during her twenty-year tenure as a teacher, she had never been observed by a colleague (Interview Transcript 10).

Interview Transcript 10

Amanda: I mean, I've taught for 20 something years...[and] I've never had this opportunity [to be observed]. So, I look forward to it.

Erika was asked what she expected to learn from the observations she was to conduct. Even though she was the mathematics department chair, it was clear she had done little (if any) observation of her mathematics teacher colleagues (Interview Transcript 11).

\section{Interview Transcript 11}

Erika: I'm not sure. I think when (pause) I'm going to have to reflect after that first day of thinking [and observing], "what happened that first day." After that first day, I'm going to have to sit back and look again because after that first day I'm not $100 \%$ sure of what I [will go] in looking for. I know it's the role of the student. I know, maybe, how actively engaged was I with the activity, how much time on task? Was there some time when I wasn't spending doing things? Um, so I'm not sure. I'm not $100 \%$; I think I'll just have to see the first day and how that works out.

Erika and her colleagues had only a vague sense of what the observer should be attending to in their mathematics classrooms because they did not have a clear sense of the role of classroom observation. The teachers implicitly knew that it was important to attend to mathematical teaching practices. However, because observation had not been a common practice, they were unaware of what specific practices were worth attending to when their colleagues make their mathematics teaching public. 


\section{DISCUSSION}

The majority of literature on teachers' professional communities take a domain-general focus (e.g., Little, 2012). For instance, analyses by Borko (2004), Shulman and Wilson (2004), and the Center for Research on the Context of Secondary School Teaching (CRC) (McLaughlin, 1993; McLaughlin \& Talbert, 2006) take a domain-general focus on teachers' knowledge of student understanding. In addition, Avalos (2011), DuFour (2004), and Louis, Kruse, and Marks (1996), described domain-general activities that are critical to the building of teachers' professional community. Further, Stoll and Louis (2007), Bryk, Camburn, and Louis (1999), Bryk and Schneider (2003), and Tharp and Gallimore (1988) highlighted trust as requisite to teachers' professional community; however, they do not address whether and how community trust may appear and operate in diverse ways across different disciplines. Finally, Newmann and Associates (1996) and Gamoran, Anderson, Quiroz, Secada, Williams, and Ashman (2003) presented key aspects of a teachers' professional community that are similarly domain-general. While some researchers (e.g., Horn \& Kane, 2015) discuss pseudo-community and professional community in the context of mathematics instruction, this does not indicate that this research is not domain-general. In Horn and Kane's article, mathematics is a background for a discussion of domain-general principles. For example, Horn and Kane describe the relationship between teacher communities and the nature of teacher talk without a domainspecific focus on teachers' mathematical talk.

The middle school mathematics teachers described in this study represent a pseudo-community (Grossman et al., 2001) because analysis of survey responses and teacher-research meeting discussion transcripts indicate that they do not have a (a) shared sense of purpose around mathematics teaching, (b) collective focus on student learning about mathematics, (c) collaborate to improve students' understanding of mathematics, (d) engage in reflective dialogue about their mathematical instructional practices, and (e) make their own mathematical teaching practices public.

The teacher responses to the teacher surveys substantiated that these teachers are members of a mathematics pseudo-community. For example, no two teachers had ever observed each other's mathematics lessons $(1 \mathrm{~b}, M d n=$ $0 ; 4 \mathrm{a}, M d n=0 ; 4 \mathrm{~b}, M d n=0$; Appendix) (Appendix B). In addition, teachers indicated that their colleagues did not support them to facilitate mathematical classroom discussions $(12 \mathrm{~d}, M d n=1.0)$ or mathematical group work $(12 \mathrm{e}, M d n=1.0)$. Moreover, teachers indicated that the administration had not structured sufficient time for mathematics department collaboration $(7, M d n=0.5)$; teachers did not discuss state mathematics standards $(6 \mathrm{j}, M d n=0.5)$ or analyze student work in mathematics $(6 \mathrm{k}, M d n=0.5)$.

This study highlights the importance of using domain-specific principles to characterize a pseudo-community. In addition, this work demonstrates the differences between domain-general and domain-specific characterizations of pseudo-community. For instance, there is minimal utility in teachers "attending to a collective focus on student learning" without a specific focus on mathematical learning. In this study Amanda discussed student tendencies to focus on mathematical procedures. Such a discussion suggests a collective focus on student learning, but not on mathematical learning. These teachers were not yet ready to collaboratively consider the relations between mathematical procedures and concepts; accordingly, they cannot be considered a professional community of mathematics teachers. In another example, Melissa collaborates to improve students' understanding. However, she does not collaborate to improve students' understanding of mathematics. This is seen when she notes, "So, maybe something that helps them see [how this content is important]...I do use this all the time...I talk about when you play football you don't just go out to practice and start playing football. You exercise and this is like exercise for your brain..." Collaboration to improve students' understanding without a focus on mathematics, does not help students develop mathematical understandings. In addition, it does not develop a professional mathematics teacher community.

\section{CONCLUSION AND IMPLICATIONS}

This mixed methods case study characterizes a group of secondary mathematics teachers according to their survey responses and interactions during a two-hour faculty meeting. The study shows that classifications of pseudo-community and professional community should attend to domain-specific properties. This work takes domain-general aspects of professional community (Gamoran, Anderson, Quiroz, Secada, Williams, \& Ashman, 2003; Newmann \& Associates, 1996) and focuses them on practices specific to teachers' professional community of mathematics.

While some research on in- and pre-service teachers' learning is orienting towards a domain-specific focus (Hill et al., 2008; Hill, 2010), there is much more work to be done. For example, Weinberg (in press) further characterizes the development of teachers' professional communities of mathematics (from teachers' pseudo-community of mathematics) through the analysis of an in-service professional development focused on leading a group discussion within a model of peer observation and de-privatization of practice. Future work should look at similar professional 
development to support teachers' professional communities of mathematics within both affluent and high-poverty schools and districts.

\section{REFERENCES}

Avalos, B. (2011). Teacher professional development in teaching and teacher education over ten years. Teaching and teacher education, 27(1), 10-20. https:/ / doi.org/10.1016/j.tate.2010.08.007

Borko, H. (2004). Professional development and teacher learning: Mapping the terrain. Educational researcher, 33(8), 3-15. https:// doi.org/10.3102/0013189X033008003

Bryk, A. S., \& Schneider, B. (2003). Trust in schools: A core resource for school reform. Educational leadership, 60(6), 40-45.

Bryk, A., Camburn, E., \& Louis, K. S. (1999). Professional community in Chicago elementary schools: Facilitating factors and organizational consequences. Educational administration quarterly, 35(5), 751-781.

DuFour, R. (2004). What is a "professional learning community"? Educational leadership, 61(8), 6-11.

Eaker, R., DuFour, R., \& DuFour, R. (2002). Getting started: Reculturing schools to become professional learning communities. Solution Tree Press.

Franke, M. L., Carpenter, T. P., Levi, L., \& Fennema, E. (2001). Capturing teachers' generative change: A follow-up study of professional development in mathematics. American educational research journal, 38(3), 653-689. https:/ / doi.org/10.3102/00028312038003653

Gamoran, A., Anderson, C. W., Quiroz, P. A., Secada, W. G., Williams, T., \& Ashman, S. (2003). Transforming teaching in math and science: How schools and districts can support change. New York: Teachers College Press.

Grossman, P., Wineburg, S., \& Woolworth, S. (2000). What Makes Teacher Community Different from a Gathering of Teachers? An Occasional Paper.

Grossman, P., Wineburg, S., \& Woolworth, S. (2001). Toward a theory of teacher community. The Teachers College Record, 103(6), 942-1012. https:/ / doi.org/10.1111/0161-4681.00140

Hill, H. C. (2010). The nature and predictors of elementary teachers' mathematical knowledge for teaching. Journal for Research in Mathematics Education, 41(5), 513-545.

Hill, H. C., Blunk, M. L., Charalambous, C. Y., Lewis, J. M., Phelps, G. C., Sleep, L., \& Ball, D. L. (2008). Mathematical knowledge for teaching and the mathematical quality of instruction: An exploratory study. Cognition and instruction, 26(4), 430-511. https:/ / doi.org/10.1080/07370000802177235

Horn, I. S., \& Kane, B. D. (2015). Opportunities for professional learning in mathematics teacher workgroup conversations: Relationships to instructional expertise. Journal of the Learning Sciences, 24(3), 373-418. https:/ / doi.org/10.1080/10508406.2015.1034865

Jordan, B., \& Henderson, A. (1995). Interaction analysis: Foundations and practice. The journal of the learning sciences, 4(1), 39-103. https://doi.org/10.1207/s15327809jls0401_2

Lave, J., \& Wenger, E. (1991). Situated learning: Legitimate peripheral participation. Cambridge, UK: Cambridge University Press. https:/ / doi.org/10.1017/CBO9780511815355

Lieberman, A., Miller, L., Wiedrick, J., \& von Frank, V. (2011). Learning communities: The starting point for professional learning is in schools and classrooms. The Learning Professional, 32(4), 16.

Little, J. W. (1982). Norms of collegiality and experimentation: Workplace conditions of school success. American educational research journal, 19(3), 325-340. https:/ / doi.org/10.3102/00028312019003325

Little, J. W. (2012). Professional community and professional development in the learning-centered school. Teacher learning that matters: International perspectives, 22-46.

Louis, K. S., Kruse, S. D., \& Marks, H. M. (1996). School wide professional community. In F.M.

Mathematics Learning Study Committee. (2001). Adding It Up: Helping Children Learn Mathematics. National Academies Press.

McLaughlin, M. (1993). What Matters Most in Teachers' Workplace Context? ln J. W. Little \& M. McLaughlin (Eds.), Teachers' Work: Individuals, Colleagues, and Contexts, (pl. 79-103). New York: Teachers College Press. American Sociological Review, 51, 464-481.

McLaughlin, M. W., \& Talbert, J. E. (2006). Building school-based teacher learning communities: Professional strategies to improve student achievement (Vol. 45). Teachers College Press.

National Governors Association. (2010). Common Core State Standards. Retrieved from http://www.corestandards.org 
Newmann \& Assoc. Authentic achievement: Restructuring schools for intellectual quality. San Francisco: Jossey-Bass (pp. 185-218).

Newmann, F. M., \& Associates. (1996). Authentic achievement: Restructuring schools for intellectual quality. San Francisco, CA: Jossey-Bass.

Peck, M. S. (1995). In search of stones: a pilgrimage of faith, reason, and discovery. Hyperion.

Resnick, L. B. (1987). Education and learning to think. National Academies.

Stoll, L., \& Louis, K. S. (2007). Professional learning communities: Divergence, depth and dilemmas. McGraw-Hill Education (UK).

Tharp, R., \& Gallimore, R. (1988). Rousing minds to life: Teaching, learning, and schooling in social contexts. Cambridge, U.K.: Cambridge University Press.

Weinberg, P. J. (accepted with minor revisions). Classroom discussion as an artifact towards teachers' professional community. International Journal for Mathematics Teaching and Learning.

Wenger, E. (1998). Communities of practice: Learning, meaning, and Identity. New York: Cambridge University Press. https:// doi.org/10.1017/CBO9780511803932 


\section{APPENDIX}

\section{Appendix A: Teacher Pre-Study Survey}

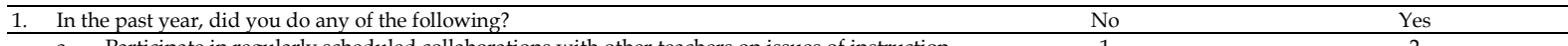
\begin{tabular}{llllcc}
\hline a. & Participate in regularly scheduled collaborations with other teachers on issues of instruction & & 1 & & \\
\hline & b. $\quad$ Observe, or be observed, by other teachers in your classroom (for at least 10 minutes) & 1 & 2 \\
\hline 2. & This question concerns how teachers interact in your school. Please indicate about how many & No & Some & Most & All
\end{tabular} \begin{tabular}{lllll} 
teachers in your school do each of the following: & Teachers & Teachers Teachers Teachers & Don't Know \\
\cline { 1 - 4 } & & 2 & 3
\end{tabular}

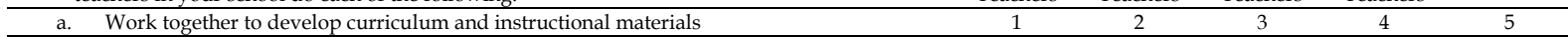

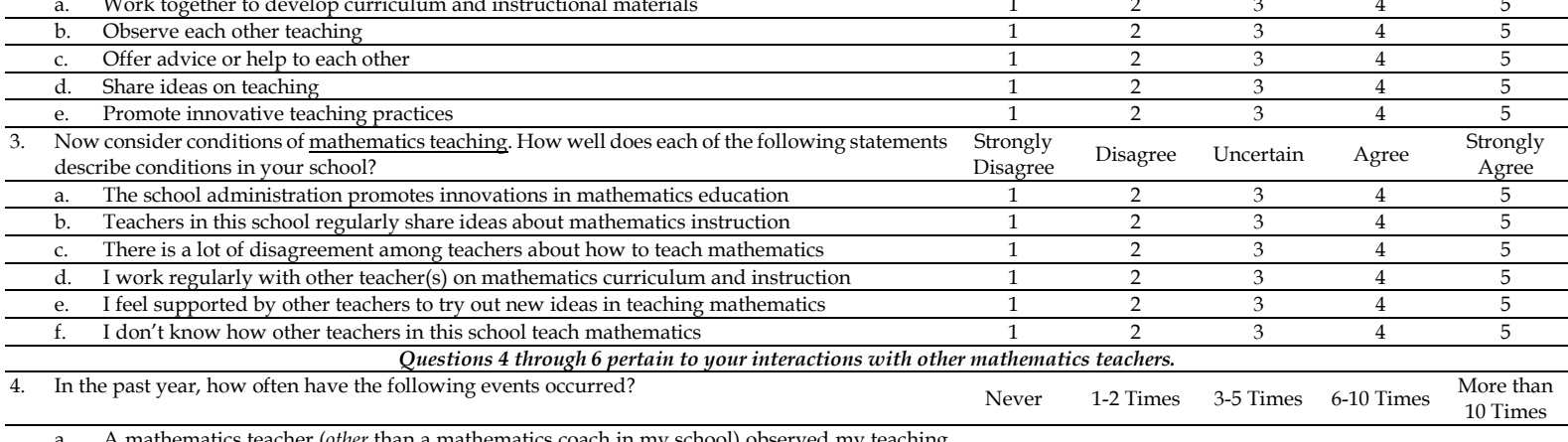
a. A mathematics teacher (other than a mathematics coach in my school) observed my teaching $\begin{array}{llllll}0 & 1 & 2\end{array}$ (for at least 10 minutes)

b. I observed a mathematics teacher teach in a classroom (for at least 10 minutes)

5. Indicate the number of teachers about whom the following statements are true: \begin{tabular}{llllll} 
b. I have detailed knowledge of the mathematics content covered by other middle school mathematics teachers at my school & 0 & 1 & 2 \\
\hline
\end{tabular} 6. In the past year, how often have you done the following with another mathematics teacher? $\quad$ Never $\quad$ 1-2 Times Quarterly Monthly At Least

\begin{tabular}{|c|c|c|c|c|c|c|}
\hline & & Never & 1-2 Times & Quarterly & Monthly & $\begin{array}{l}\text { At Least } \\
\text { Weekly }\end{array}$ \\
\hline a. & Discussed administrative tasks and how to fulfill them & 0 & 1 & 2 & 3 & 4 \\
\hline b. & Discussed/clarified the key mathematical ideas in a particular lesson or unit & 0 & 1 & 2 & 3 & 4 \\
\hline c. & Discussed mathematical ideas that are usually difficult for students to understand & 0 & 1 & 2 & 3 & 4 \\
\hline d. & Discussed different ways in which students solve a particular problem & 0 & 1 & 2 & 3 & 4 \\
\hline e. & Jointly planned for instruction & 0 & 1 & 2 & 3 & 4 \\
\hline f. & Shared materials related to mathematics instruction & 0 & 1 & 2 & 3 & 4 \\
\hline g. & Discussed how to manage classroom routines and procedures (e.g., collecting homework) & 0 & 1 & 2 & 3 & 4 \\
\hline h. & Discussed how to organize the classroom for instruction (e.g., small groups, whole class, etc.) & 0 & 1 & 2 & 3 & 4 \\
\hline i. & Discussed the behavior of specific students & 0 & 1 & 2 & 3 & 4 \\
\hline j. & Clarified our understanding of the state standards in math & 0 & 1 & 2 & 3 & 4 \\
\hline k. & Discussed students' work & 0 & 1 & 2 & 3 & 4 \\
\hline
\end{tabular}
k. Discussed students' work

Questions 7 through 18 pertain to your interactions with your school principal (or assistant principals).

7. Did your principal structure this school year's schedule to provide time for collaboration with your mathematics department or your cross-disciplinary team?

8. How often does the schedule your principal created this school year provide common time for mathematics teachers' collaboration?

9. In the past year, how often have the following events occurred?

\begin{tabular}{|c|c|c|c|c|}
\hline \multicolumn{2}{|r|}{ No } & \multicolumn{3}{|c|}{ Yes } \\
\hline \multicolumn{2}{|r|}{0} & \multicolumn{3}{|c|}{1} \\
\hline Daily & Week & & Monthly & Quarterly \\
\hline 1 & 2 & & 3 & 4 \\
\hline Never & 1-2 Times & Quarterly & Monthly & $\begin{array}{l}\text { At Least } \\
\text { Weekly }\end{array}$ \\
\hline 0 & 1 & 2 & 3 & 4 \\
\hline 0 & 1 & 2 & 3 & 4 \\
\hline 0 & 1 & 2 & 3 & 4 \\
\hline Not at All & $\begin{array}{r}\text { To a Si } \\
\text { Exte }\end{array}$ & $\begin{array}{l}\text { nall } \\
\text { t }\end{array}$ & $\begin{array}{l}\text { Moderate } \\
\text { Extent }\end{array}$ & $\begin{array}{c}\text { To a Great } \\
\text { Extent }\end{array}$ \\
\hline 1 & 2 & & 3 & 4 \\
\hline 1 & 2 & & 3 & 4 \\
\hline 1 & 2 & & 3 & 4 \\
\hline 1 & 2 & & 3 & 4 \\
\hline $\begin{array}{l}\text { Strongly } \\
\text { Disagree }\end{array}$ & Disag & & Agree & Strongly Agree \\
\hline
\end{tabular}

11. To what extent do you agree or disagree with the following statements? Disagree

2
assist me in improving my teaching

b. The purpose of my school principal (or assistant principal) visiting my classroom is to evaluate my teaching in terms of job performance

12. In the past year, who has expected you to do the following activities: Mark all that apply. $\quad$ No One $\quad$ Other Teachers Principals $\quad$ Math Coach

\begin{tabular}{|c|c|c|c|c|c|}
\hline a. & Adhering to a prescribed pacing in my instruction & 1 & 2 & 3 & 4 \\
\hline b. & Making sure that my students' test scores are high & 1 & 2 & 3 & 4 \\
\hline c. & Addressing the state/district objectives and standards & 1 & 2 & 3 & 4 \\
\hline d. & Having whole classroom discussion in which students explain how they solved tasks & 1 & 2 & 3 & 4 \\
\hline e. & Having small-group discussion in which students explain how they solved tasks & 1 & 2 & 3 & 4 \\
\hline f. & Using the adopted curriculum as a basis for my classroom instruction & 1 & 2 & 3 & 4 \\
\hline g. & Keeping my students quiet and disciplined during classroom instruction & 1 & 2 & 3 & 4 \\
\hline h. & Using challenging, non-routine tasks with my students & 1 & 2 & 3 & 4 \\
\hline i. & Collaborating with other mathematics teachers & 1 & 2 & 3 & 4 \\
\hline j. & Participating in professional development beyond district or school requirements & 1 & 2 & 3 & 4 \\
\hline k. & Observing other mathematics teachers' instructional practices & 1 & 2 & 3 & 4 \\
\hline 1. & Using him/her/them as a resource when instructional problems arose & 1 & 2 & 3 & 4 \\
\hline $\mathrm{m}$. & Making my lesson plans available for inspection & 1 & 2 & 3 & 4 \\
\hline n. & Trying new instructional approaches in my classroom & 1 & 2 & 3 & 4 \\
\hline
\end{tabular}

m. Making my lesson plans available for inspection

a. I discussed my teaching with a school principal or an assistant principal

A school principal or an assistant principal observed my teaching (for at

a. Worked with me to resolve student behavioral problems in my classroom Provided me with feedback to improve my instruction after observing my teaching Enabled me to purchase additional instructional materials that I needed

d. Appreciated challenges in using the curriculum effective 


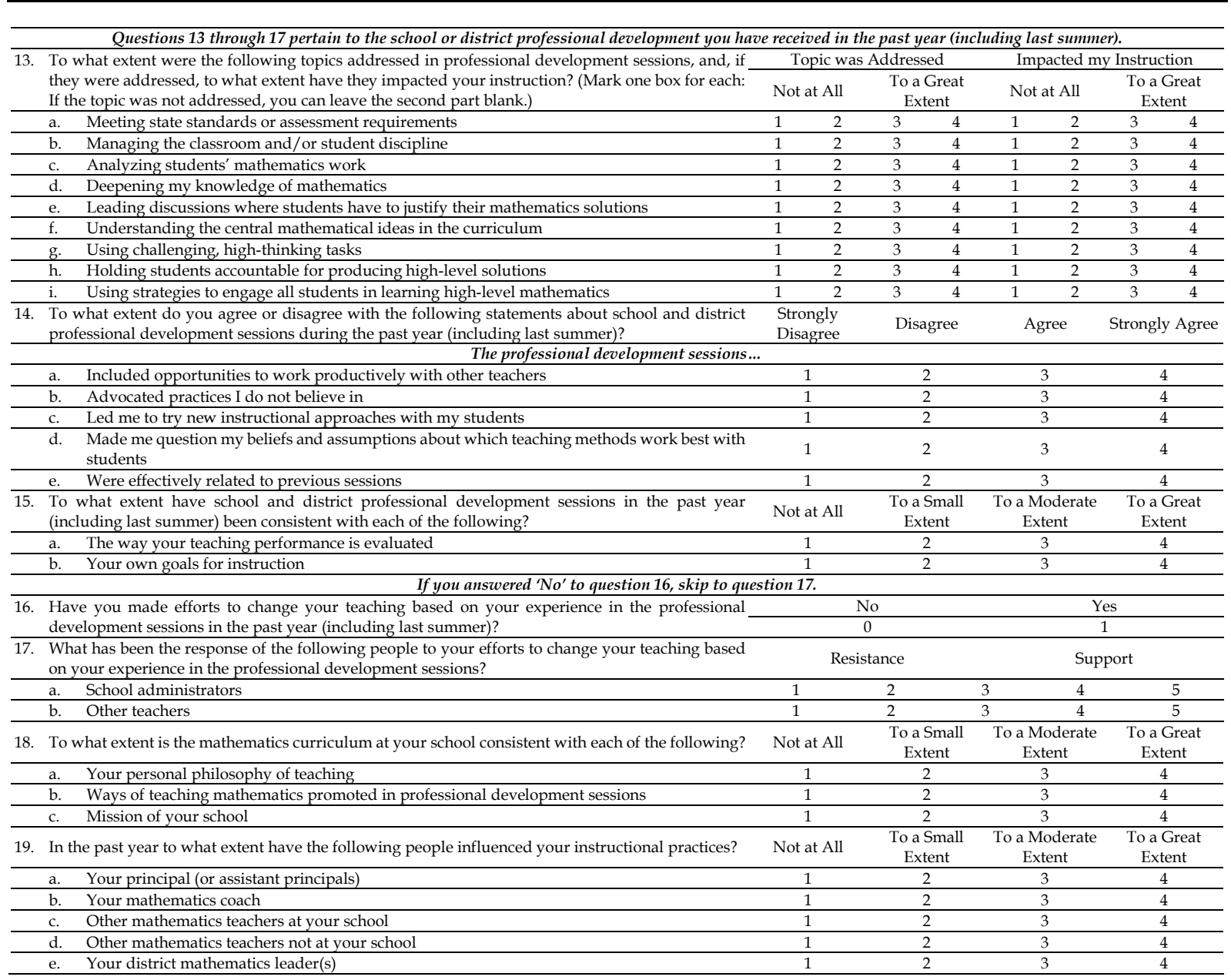

\section{Appendix B: Survey Items, Teacher Median Scores, and P-values}

\begin{tabular}{|c|c|c|}
\hline Item & Median & p-value \\
\hline 1a & 1.00 & $p<0.05$ \\
\hline $1 \mathrm{~b}$ & 0.00 & $p<0.01$ \\
\hline $2 a$ & 2.00 & $p<0.05$ \\
\hline $2 b$ & 2.50 & $p<0.01$ \\
\hline $2 c$ & 3.00 & $p<0.01$ \\
\hline $2 \mathrm{~d}$ & 3.00 & $p<0.01$ \\
\hline $2 \mathrm{e}$ & 2.50 & $\mathrm{p}<0.01$ \\
\hline $3 a$ & 4.50 & $p<0.01$ \\
\hline $3 b$ & 3.50 & $p<0.05$ \\
\hline $3 c$ & 2.00 & $p<0.05$ \\
\hline $3 \mathrm{~d}$ & 2.50 & $p<0.05$ \\
\hline $3 e$ & 4.00 & $p<0.05$ \\
\hline $3 \mathrm{f}$ & 3.00 & $\mathrm{p}<0.05$ \\
\hline $4 \mathrm{a}$ & 0.00 & $\mathrm{p}=0.92$ \\
\hline $4 \mathrm{~b}$ & 0.00 & $\mathrm{p}=0.92$ \\
\hline $5 a$ & 1.00 & $p<0.05$ \\
\hline $5 b$ & 1.00 & $\mathrm{p}<0.05$ \\
\hline $6 a$ & 1.50 & $p<0.05$ \\
\hline $6 \mathrm{~b}$ & 1.00 & $p<0.05$ \\
\hline $6 c$ & 1.50 & $p<0.05$ \\
\hline $6 \mathrm{~d}$ & 1.50 & $p<0.05$ \\
\hline $6 e$ & 0.50 & $p=0.07$ \\
\hline $6 f$ & 1.00 & $p=0.14$ \\
\hline $6 \mathrm{~g}$ & 1.00 & $p<0.05$ \\
\hline $6 \mathrm{~h}$ & 1.00 & $p<0.05$ \\
\hline $6 \mathrm{i}$ & 1.50 & $p<0.05$ \\
\hline $6 \mathrm{j}$ & 0.50 & $p=0.07$ \\
\hline $6 \mathrm{k}$ & 0.50 & $\mathrm{p}=0.07$ \\
\hline 7 & 0.50 & $p=0.07$ \\
\hline 8 & 4.00 & $p=0.14$ \\
\hline $9 a$ & 1.50 & $p<0.05$ \\
\hline $9 \mathrm{~b}$ & 1.00 & $p<0.01$ \\
\hline $9 \mathrm{c}$ & 1.00 & $p=0.07$ \\
\hline
\end{tabular}


EURASIA J Math Sci and Tech Ed

\begin{tabular}{|c|c|c|}
\hline $10 \mathrm{a}$ & 1.50 & $p=0.07$ \\
\hline $10 \mathrm{~b}$ & 1.50 & $p<0.05$ \\
\hline $10 \mathrm{c}$ & 2.00 & $p<0.05$ \\
\hline $10 \mathrm{~d}$ & 3.00 & $\mathrm{p}=0.10$ \\
\hline $11 a$ & 3.00 & $p<0.01$ \\
\hline $11 \mathrm{~b}$ & 3.00 & $p<0.01$ \\
\hline $12 a$ & 2.00 & $p=0.09$ \\
\hline $12 \mathrm{~b}$ & 3.00 & $p<0.01$ \\
\hline $12 \mathrm{c}$ & 2.00 & $p<0.05$ \\
\hline $12 \mathrm{~d}$ & 1.00 & $p=0.14$ \\
\hline $12 \mathrm{e}$ & 1.00 & $\mathrm{p}=0.92$ \\
\hline $12 \mathrm{f}$ & 3.00 & $p<0.05$ \\
\hline $12 \mathrm{~g}$ & 1.50 & $p=0.09$ \\
\hline $12 \mathrm{~h}$ & 2.00 & $\mathrm{p}=0.09$ \\
\hline $12 \mathrm{i}$ & 3.00 & $p<0.01$ \\
\hline $12 j$ & 2.00 & $\mathrm{p}=0.09$ \\
\hline $12 \mathrm{k}$ & 1.00 & $\mathrm{p}=0.46$ \\
\hline 121 & 2.00 & $p<0.05$ \\
\hline $12 \mathrm{~m}$ & 3.00 & $p<0.05$ \\
\hline $12 n$ & 1.00 & $p=0.19$ \\
\hline $13 a_{1}$ & 3.50 & $p<0.05$ \\
\hline $13 \mathrm{a}_{2}$ & 3.00 & $p<0.05$ \\
\hline $13 b_{1}$ & 1.50 & $p=0.07$ \\
\hline $13 b_{2}$ & 3.50 & $p=0.92$ \\
\hline $13 c_{1}$ & 2.00 & $p<0.05$ \\
\hline $13 c_{2}$ & 2.00 & $p<0.05$ \\
\hline $13 d_{1}$ & 2.50 & $p<0.05$ \\
\hline $13 \mathrm{~d}_{2}$ & 2.00 & $p=0.10$ \\
\hline $13 \mathrm{e}_{1}$ & 2.50 & $\mathrm{p}<0.05$ \\
\hline $13 \mathrm{e}_{2}$ & 2.00 & $p=0.10$ \\
\hline $13 \mathrm{f}_{1}$ & 2.00 & $p<0.05$ \\
\hline $13 \mathrm{f}_{2}$ & 1.33 & $\mathrm{p}=0.14$ \\
\hline $13 \mathrm{~g}_{1}$ & 2.00 & $p<0.05$ \\
\hline $13 g_{2}$ & 2.00 & $p=0.14$ \\
\hline $13 \mathrm{~h}_{1}$ & 1.00 & $p=0.17$ \\
\hline $13 \mathrm{~h}_{2}$ & 1.00 & $p=0.14$ \\
\hline $13 \mathrm{i}_{1}$ & 2.00 & $p<0.05$ \\
\hline $13 \mathrm{i}_{2}$ & 2.00 & $\mathrm{p}=0.14$ \\
\hline $14 a$ & 3.00 & $p<0.01$ \\
\hline $14 \mathrm{~b}$ & 1.00 & $p=0.19$ \\
\hline $14 \mathrm{c}$ & 3.00 & $p<0.01$ \\
\hline $14 \mathrm{~d}$ & 2.00 & $p<0.05$ \\
\hline $14 \mathrm{e}$ & 3.00 & $p<0.01$ \\
\hline $15 a$ & 1.00 & $p=0.19$ \\
\hline $15 b$ & 3.50 & $p<0.01$ \\
\hline 16 & 1.00 & $p<0.05$ \\
\hline $17 \mathrm{a}$ & 3.50 & $p<0.01$ \\
\hline $17 \mathrm{~b}$ & 3.50 & $p<0.01$ \\
\hline $18 \mathrm{a}$ & 4.00 & $p<0.01$ \\
\hline $18 \mathrm{~b}$ & 4.00 & $\mathrm{p}<0.01$ \\
\hline $18 \mathrm{c}$ & 2.00 & $\mathrm{p}<0.01$ \\
\hline $19 a$ & 2.00 & $p<0.05$ \\
\hline $19 b$ & 2.00 & $p=0.14$ \\
\hline $19 \mathrm{c}$ & 2.50 & $p<0.05$ \\
\hline $19 \mathrm{~d}$ & 2.00 & $p<0.05$ \\
\hline $19 \mathrm{e}$ & 2.00 & $\mathrm{p}<0.05$ \\
\hline
\end{tabular}

Note. P-values indicate Mann-Whitney U Test difference between teacher endorsed survey values and the lowest possible survey value. See survey (Appendix A)

\section{http://www.ejmste.com}

